\title{
Migraine patients consistently show abnormal vestibular bedside tests
}

\author{
Pacientes enxaquecosos consistentemente apresentam testes vestibulares de \\ beira-de-leito anormais \\ Eliana Teixeira Maranhão ${ }^{1,2}$, Péricles Maranhão-Filho ${ }^{3}$, Ronir Raggio Luiz ${ }^{4}$, Maurice Borges Vincent ${ }^{3}$
}

\begin{abstract}
Migraine and vertigo are common disorders, with lifetime prevalences of $16 \%$ and $7 \%$ respectively, and co-morbidity around $3.2 \%$.Vestibular syndromes and dizziness occur more frequently in migraine patients. We investigated bedside clinical signs indicative of vestibular dysfunction in migraineurs. Objective: To test the hypothesis that vestibulo-ocular reflex, vestibulo-spinal reflex and fall risk (FR) responses as measured by 14 bedside tests are abnormal in migraineurs without vertigo, as compared with controls. Method: Cross-sectional study including sixty individuals - thirty migraineurs, 25 women, 19-60 y-0; and 30 gender/age healthy paired controls. Results: Migraineurs showed a tendency to perform worse in almost all tests, albeit only the Romberg tandem test was statistically different from controls. A combination of four abnormal tests better discriminated the two groups ( $93.3 \%$ specificity). Conclusion: Migraine patients consistently showed abnormal vestibular bedside tests when compared with controls.
\end{abstract}

Keywords: migraine, vertigo, bedside tests.

\section{RESUMO}

Enxaqueca e vertigem são desordens comuns, com prevalência de 16\% e 7\% respectivamente, e comorbidade em torno de 3,2\%. Síndromes vestibulares e tonturas ocorrem mais frequentemente em enxaquecosos. Pesquisamos alterações vestibulares utilizando testes de beira-de-leito em enxaquecosos. Objetivo: Verificar se as respostas dos reflexos vestíbulo-ocular, vestíbulo-medular e risco de quedas medidas por 14 testes de beira-de-leito são diferentes comparando-se enxaquecosos sem vertigem, e controles. Método: Estudo transversal com sessenta pessoas, 30 enxaquecosos; 25 mulheres, 19-60 anos; e trinta controles saudáveis pareados por sexo e idade. Resultados: Houve tendência de pior desempenho entre enxaquecosos em quase todos testes, porém apenas o teste de Romberg tandem foi estatisticamente diferente dos controles. Uma combinação de quatro testes anormais discrimina os grupos com especificidade de 93,3\%. Conclusão: 0 grupo de enxaquecosos mostrou consistentemente testes vestibulares de beira-de-leito anormais quando comparados a controles.

Palavras-chave: enxaqueca, vertigem, testes de beira-de-leito.

In neurological and otorrinolaryngological outpatients units migraine and vertigo are the two most common complains ${ }^{1}$. Vestibular syndromes, dizziness, vertiginous syndromes as benign positional paroxysmal vertigo, Ménière disease, motion sickness, cerebellar and anxiety disorders, in whom very often dizziness is present, all occur more frequently amongst migraineurs $(30-50 \%)^{2,3,4}$. It is well known that the equilibrium depends on an interplay between vestibular mechanisms, proprioception and visual inputs. Available data suggest that this circuitry could be dysfunctional in migraine. However, the issue as how, why and to which extent vestibular changes do occur in those subjects remains highly controversial. The objective of the present study was to test the hypothesis that bedside clinical tests specifically designed to detect subtle vestibular dysfunctions are abnormal in migraine in the absence of vestibular complains.

\section{METHOD}

In this cross sectional study, 30 (ICHD-2004, $2^{\text {nd }}$ Ed. Cod:1; 1.1 and 1.2) interictal phase migraine patients, sequentially

${ }^{1}$ Instituto Nacional de Câncer (INCA), Setor de Fisioterapia, Rio de Janeiro RJ, Brazil;

${ }^{2}$ American Physical Therapy Association for Vestibular Rehabilitation, Alexandria VA, USA;

${ }^{3}$ Universidade Federal do Rio de Janeiro, Hospital Universitário Clementino Fraga Filho, Serviço de Neurologia, Rio de Janeiro RJ, Brazil;

«Universidade Federal do Rio de Janeiro, Instituto de Estudos de Saúde Pública, Rio de Janeiro RJ, Brazil.

Correspondence: Eliana Teixeira Maranhão; Avenida das Américas, 1155/1705; 22631-000 Rio de Janeiro RJ, Brasil; E-mail: limaranhao@gmail.com

Conflict of interest: There is no conflict of interest to declare.

Received 26 June 2015; Received in final form 12 August 2015; Accepted 01 September 2015. 
recruited in our unit and 30 matched healthy controls (patients partners and medical students) were blindly examined by the same researcher (ETM) after diagnosis. Inclusion and exclusion criteria were checked by well-trained neurologists with long headache expertise (PM-F and MBV). All tests ${ }^{5-18}$ (Table 1), were performed during one single session at the same hospital facility. Inclusion criteria were age between 18 and 65 years; migraine for at least 2 years with a minimum frequency of 2 attacks montly; and at least 1 brain Magnetic Ressonance (MRI) or Computerized Tomography (CT) scan within normal limits. Exclusion criteria were informed or clinically evidenced pregnancy; two or more tension-type headache episodes (ICHD-2004, $2^{\text {nd }} \mathrm{Ed}$. Cod:2; 2.1, 2.2) in the previous week, chronic tension type headache (coded 2.3) or

Table 1. Tests for Vestibulo-ocular Reflex (VOR), Vestibulo-spinal Reflex (VSR) and fall risk (FR) used in clinical evaluation.

Clinical test
$\begin{aligned} & \text { Head Impulse Test } \\ & (\text { HIT })^{5}\end{aligned}$
Head Shaking Test
$(\text { HST })^{6}$
Dynamic Visual Acuity
$(\text { DVA) })^{7}$
Subjective Visual
Vertical (SVV)

Minimal Ice Test $(\mathrm{MIT})^{9}$

\author{
Modified Clinical Test \\ of Sensory Interaction \\ and Balance \\ $(\mathrm{mCTSIB})^{10}$ \\ Romberg Tandem Test \\ $(\mathrm{RTT})^{11}$
} Past Pointing Test
$(\text { PPT) })^{12}$

Fukuda Test $(\mathrm{FT})^{13}$

Timed Up and Go

$(T \cup G)^{14}$

5 Times Sit to Stand Test (5TSST) ${ }^{15}$

Forward Reaching Test $(\text { FRT })^{16}$

Dynamic Gait Index $(\mathrm{DGI})^{17}$

Pull Test $(\mathrm{PT})^{18}$

\section{Method \\ Vestibulo-Ocular Reflex}

Clinician, facing and holding the subject's head at arm's length, performs a passive and unpredictable head rotational movement in a high acceleration $\sim 20^{\circ}$ to either side having the subject's eyes fixed on the examiner's nose. I may also be done vertically (Figure 1A, B, C).

Subject's wearing Frenzel goggle with the head positioned downwards by $30^{\circ}$. The examiner rapidly oscillate the head $(2 \mathrm{~Hz}) 20$ times. When the movement stops the clinician observes the presence of nystagmus.

Subject reads the lowest possible line in a ETDRS chart positioned 2 meters ahead, than the examiner manually oscillates the subject's head horizontally at 2

$\mathrm{Hz}$ in each direction and the subject tries to read the same line (Figure 1D, E).

Looking inside a bucket, without any peripheral vision, the subject vertically redirect a line drawn on the inner bottom of the bucket under the subject's subjective perception. Results measured outside with a pendulum hanging over a protractor (Figure 1F, G, H).

Subject is fitted with a Frenzel goggle and $0.2 \mathrm{~mL}$ iced water $\left(1-3^{\circ} \mathrm{C}\right)$ is plunged in the ear canal with the head turned to side and bended $30^{\circ}$ forward. After $10 \mathrm{sec}$ the head is turned straigth and nystagmus is observed in the computer screen. After $5 \mathrm{~min}$ the same procedure is performed on the other ear.

\section{Vestibulo Spinal Reflex}

The subject stands on a firm surface with the feet slightly apart and crossed arms, first with eyes open and than with eyes closed, for 30 sec each. The same manoeuvre is repeated on a high density foam (Figure 2D).

Subject stand with feet slightly apart and arms folded across the chest with eyes open for 30 seconds and then with eyes closed for 30 seconds.

The subject is instructed to extend the arms and place the index finger of one hand on the index finger of the examiner. The eyes are then closed, the arm raised above the head, then quickly returned to the perceived starting position. The procedure is repeated five times (Figure 2A, B, C).

Subject with arms extended and eyes closed, stepping in place with examiner counting for 50 steps (Figure 2E, F).

\section{Fall Risk}

Subject rises from a standard height chair with armrests, walks $3 \mathrm{~m}$, turns, and returns to sit in the chair. The time to complete the path is measured with a stopwatch.

Subject seated in a chair with arms crossed under chest and feet fitted on the ground. Upon request, stands up and sit down for 5 times. Time measured with a stopwatch.

Subject is asked to bend the trunk and reach as far forward as possible having both feet fixed and parallel. The extent of movement is measured with a simple yardstick.

The subject is observed during an eight-item task within a 21 feet path walking.

The subject stands with the feet slightly spread apart and is pulled backward by the shoulders (one or two steps backwards allowed) (Figure 2G).
Corrective saccade back to the target

Nystagmus; more than 5 beats

Deviation of more than 2 lines above base line

More than $2.5^{\circ}$ deviation from $0^{\circ}$ to either side

$\neq$ between ears responses $>25 \%=$ canal paresis

Normal and Minimal sway: grades 1 and 2. Moderate and Severe: grades 3 and 4

Marked sway, or: move the feet, open the eyes, uncross the arms

Index drift away from the target towards the compromised side

Moves more than $50 \mathrm{~cm}$ ahead and turns toward one side of more than $45^{\circ}$

More than 13.5 sec to complete the task

More than 10 seconds to complete the task

Score $15 \mathrm{~cm}$ or less indicate high risk for fall

Score of 19 or less out of 24 points

More than 2-3 steps to keep the balance or fall backward like a log 
other headache listed in groups 3-4 (ICHD, 2004) according to clinical evaluation; circulatory, respiratory, orthopedic abnormalities or generalized weakness/tiredness of any nature which could influence/preclude the clinical tests; Ménière disease, vestibular neuritis, benign positional paroxysmal vertigo or phobic vertigo; spontaneous nystagmus; any sensitive, sensorineural, motor or coordination deficits; more than $150 \mathrm{~mL}$ coffee, 3 tea cups, or 2 soda cans intake per day for the last 2 days, or any amount of alcoholic beverages, tobacco, anti-vertiginous drugs, anti-depressive, anxiolytic antiemetic, or pain-killers more than b.i.d. use. All subjects underwent a neurootological examination including the minimal ice test (MIT) ${ }^{9}$. For the MIT a difference between right and left responses greater than $25 \%$ was considered as a canal paresis ${ }^{19}$. The Wilcoxon Signed Rank, the McNemar chisquare, and the Student $t$ test were used for statistical comparisons; p-values $<0.05$ were considered significant. The local Ethics Committee approved this study (Protocol:159-11).

\section{RESULTS}

Participants were mostly females (83.3\%). Migraine patients were aged 19-62 (median 39.3) years and controls 22-62 (median 38.9) years. Considering all tests together there was a clear tendency for migraineurs to perform worse than controls $(p=0.003)$, except for the SVV and the FRT (Table 2). The tests involving the vestibulo-ocular reflex (VOR) assessment (Figure 1) in general did not distinguish patients from healthy controls $(\mathrm{p}<0.05)$.

For the MIT the nystagmus duration ranged from 16 to 218 seconds in patients. The average percentage difference between R-L ears was $20.97 \pm 15.9 \%$ in the patients group and $18 \pm 11.5 \%$ in controls (Figure 2).

Regarding the vestibulo-spinal reflex (VSR) (Figure 3), only the RTT was statistically different between the two groups ( $\mathrm{p}=0.039$ ). For the the $\mathrm{m}$-CTSIB, considering only the responses graded as 3 and 4 , six migraine patients (20\%) and three control subjects (10\%) showed abnormal responses.

The 5TSST and the PT tests were nearly statistically different ( $p=0,074)$ in contrast with other Fall Risk (FR) tests.

A combination of 4 abnormal tests distinguish patients from controls with a sensitivity of $23.3 \%$ and a specificity of 93.3\% (Table 3).

\section{DISCUSSION}

The present study shows that vertigo-free migraine patients, during the interictal phase, perform worse than controls in bedside clinical vestibular tests independently from vestibular complains.

Although various techniques may be used to address the vestibular function in migraine patients with or without vertigo $^{20-25}$, data considering vestibular bedside tests in this context are scarce.

Marcelli et al. ${ }^{26}$ evaluated otoneurological abnomalities in 22 migraineurs with vestibular symptoms as compared with 18 control migraineurs without vestibular symptoms. Seventy-three percent of the subjects in the first group had vestibular dysfunctions - peripheral, central or both - contrasting with $33 \%$ in the second group. The authors suggest the presence of a subclinical vestibular system involvement in the vertigo-free migraine patients.

Chronic headache causes postural instability, which could be the result of a sensory information rearrangement leading to greater vestibular system contribution paralleled by a reduced visual component in the equilibrium control ${ }^{24}$. If this is true, migraineurs would be comparatively more dependent on vestibular functions for postural control, justifying the present results.

The tests we used to evaluate the VOR were not statistically different comparing the two groups. The response evoked by high accelerations (HIT) is controlled by a variety of different sensory and motor systems apart from the vestibular system. The VOR response can change within few minutes, pointing to a VOR plasticity ${ }^{7}$, but this is probably not sufficient to overcome the inadequate vestibular inputs and generate adequate responses. It is possible that chronic migraineurs develop the same phenomena identified in subjects with loss of vestibular function such as hidden saccades or other strategies to compensate a putative vestibular failure. Likewise, patients may increase the gain of the cervico-ocular reflex, and possibly the smooth pursuit system.

The DVA clearly tended to show worse results amongst patients although the SVV assessment was quite similar in both groups. Neck stiffness could putatively interfere with the DVA, as it has been shown that neck motility may be impaired in migraine ${ }^{27}$.

MIT is a clean and quick monothermal bedside test, essentially a low-frequency stimulus caloric test that can detect vestibular impairment not apparent during higher-frequency head rotation ${ }^{28,29}$. In accordance with the other tests, data also point to a vestibular instability in migraineurs, as reflected by a greater right-to-left asymmetry and a greater response spread amongst patients.

Apropos the VSR tests, Akdal et al..$^{30}$ carried out a balance and gait comparative study in 30 patients with vestibular migraine, 26 migraine without vertigo subjects, and 30 individuals whithout migraine. Among other tests and scales they also used the CTSIB and the DGI, concluding that vestibular migraine sufferers, defined according to the Lempert and Neuhauser criteria ${ }^{4}$, as well as the migraineurs without vertigo, presented subnormal static and dynamic balance, as well as increased fall risk (FR). Góes ${ }^{31}$ used a stabilometric test to assess the static equilibrium of migraine patients interictally. The stabilometric parameters did not differ between patients and controls. However, migraine with aura 
Table 2. Distribution of the tests for the Vestibulo-ocular Reflex, Vestibulo-spinal Reflex and Fall Risk in 30 migraine patients and 30 controls, paired for age and sex.

\begin{tabular}{|c|c|c|c|c|c|}
\hline \multirow{2}{*}{ Parameter } & \multirow{2}{*}{$\begin{array}{c}\text { Group } \\
\text { Migraine }\end{array}$} & \multirow{2}{*}{ Total (\%) } & \multicolumn{2}{|c|}{ Control Group } & \multirow{2}{*}{ P-value* } \\
\hline & & & Normal & Abnormal & \\
\hline \multirow[t]{3}{*}{ HIT } & Normal & $19(63.3)$ & 16 & 3 & 0.344 \\
\hline & Abnormal & $11(36.7)$ & 7 & 4 & \\
\hline & Total (\%) & $30(100.0)$ & $23(76.7)$ & $7(23.3)$ & \\
\hline \multirow[t]{3}{*}{ HST } & Normal & 28 (93.3) & 28 & 0 & 0.248 \\
\hline & Abnormal & $2(6.7)$ & 2 & 0 & \\
\hline & Total (\%) & 30 (100.0) & $30(100.0)$ & $0(0.0)$ & \\
\hline \multirow[t]{3}{*}{ DVA } & Normal & $17(56.7)$ & 13 & 4 & 0.267 \\
\hline & Abnormal & $13(43.3)$ & 9 & 4 & \\
\hline & Total (\%) & $30(100.0)$ & $22(73.3)$ & $8(26.7)$ & \\
\hline \multirow[t]{3}{*}{ SVV } & Normal & $26(86.7)$ & 23 & 3 & 1.000 \\
\hline & Abnormal & $4(13.3)$ & 3 & 1 & \\
\hline & Total (\%) & 30 (100.0) & $26(86.7)$ & 4 (13.3) & \\
\hline \multirow[t]{3}{*}{ mCTSIB } & Normal & $24(80.0)$ & 23 & 1 & 0.375 \\
\hline & Abnormal & $6(20.0)$ & 4 & 2 & \\
\hline & Total (\%) & 30 (100.0) & $27(90.0)$ & $3(10.0)$ & \\
\hline \multirow[t]{3}{*}{ RTT } & Normal & 19 (63.3) & 17 & 2 & 0.039 \\
\hline & Abnormal & $11(36.7)$ & 10 & 1 & \\
\hline & Total (\%) & 30 (100.0) & $27(90.0)$ & $3(10.0)$ & \\
\hline \multirow[t]{3}{*}{ PPT } & Normal & $24(80.0)$ & 20 & 4 & 0.754 \\
\hline & Abnormal & $6(20.0)$ & 6 & 0 & \\
\hline & Total (\%) & $30(100.0)$ & $26(86.7)$ & $4(13.3)$ & \\
\hline \multirow[t]{3}{*}{ FT } & Normal & $13(43.3)$ & 8 & 5 & 0.302 \\
\hline & Abnormal & $17(56.7)$ & 10 & 7 & \\
\hline & Total (\%) & $30(100.0)$ & $18(60.0)$ & $12(40.0)$ & \\
\hline \multirow[t]{3}{*}{ TUG } & Normal & $29(96.7)$ & 29 & 0 & 0.479 \\
\hline & Abnormal & $1(3.3)$ & 1 & 0 & \\
\hline & Total (\%) & 30 (100.0) & $30(100.0)$ & $0(0.0)$ & \\
\hline \multirow[t]{3}{*}{ 5TSST } & Normal & $26(86.7)$ & 26 & 0 & 0.074 \\
\hline & Abnormal & $4(13.3)$ & 4 & 0 & \\
\hline & Total (\%) & 30 (100.0) & $30(100.0)$ & $0(0.0)$ & \\
\hline \multirow[t]{3}{*}{ RFT } & Normal & 30 (100.0) & 30 & 0 & 1.000 \\
\hline & Abnormal & $0(0.0)$ & 0 & 0 & \\
\hline & Total (\%) & $30(100.0)$ & $30(100.0)$ & $0(0.0)$ & \\
\hline \multirow[t]{3}{*}{ DGI } & Normal & $26(86.7)$ & 25 & 1 & 0.375 \\
\hline & Abnormal & $4(13.3)$ & 4 & 0 & \\
\hline & Total (\%) & $30(100.0)$ & $29(96.7)$ & $1(3.3)$ & \\
\hline \multirow[t]{3}{*}{ PT } & Normal & $26(86.7)$ & 26 & 0 & 0.074 \\
\hline & Abnormal & $4(13.3)$ & 4 & 0 & \\
\hline & Total (\%) & 30 (100.0) & $30(100.0)$ & $0(0.0)$ & \\
\hline
\end{tabular}

HIT: Head Impulse Test; HST: Head Shaking Test; DVA: Dynamic Visual Acuity; SVV: Subjective Visual Vertical; MIT: Minimal Ice Test; mCTSIB: Modified Clinical Test of Sensory Interaction and Balance; RTT: Romberg Tandem Test; PPT: Past Pointing Test; FT: Fukuda Test; TUG:Time Up and Go; 5TSST: 5 Times Sit to Stand Test; FRT: Forward Reaching Test; DGI: Dynamic Gait Index; PT: Pull Test. * Chi-square test of McNemar.

patients showed a significantly greater lateral oscillation than migraineurs without aura. In our study, the RTT was the most sensitive test, pointing to a dysfunction of the static equilibrium in migraineurs. Given the clearly unfavorable result for RTT it is possible that the dysfunction in migraine would be greater in the VSR mechanisms specially involving proprioceptive impulses. In the m-CTSIB test, when the subject is placed on the foam, the proprioceptive influence to the postural reflex drops by approximately $60 \%^{7}$. Although the patients had no anteroposterior imbalance predominance, the migraneurs had three times more abnormal tests than controls, indicating that in migraine the vestibular influence on the posture control is comparatively dysfunctional. It remains to be explained wheather this is secondary to impaired neck and/or labyrith abnormal reflexes in migraine, as they could modulate the muscular tonus. Stretch reflexes receive important contribution from vestibulo-spinal responses, proprioceptive signs from the trunk and neck, or both, 
visual stimulus, and vonluntary responses ${ }^{32}$. Therefore, it is possible the subnormal vestibular function in migraine could increase the FR by stretch reflexes impairment.

In patients, the FR tests pointed to a subtle fall tendency. Only one patient showed increased FR according to the TUG test. Four migraneurs (13.3\%), showed increased FR in the 5TSST, while none of the controls exceeded this test time limits (10 and 14.2 seconds, according to age). According to the FRT none of the sixty examined subjects showed an increased
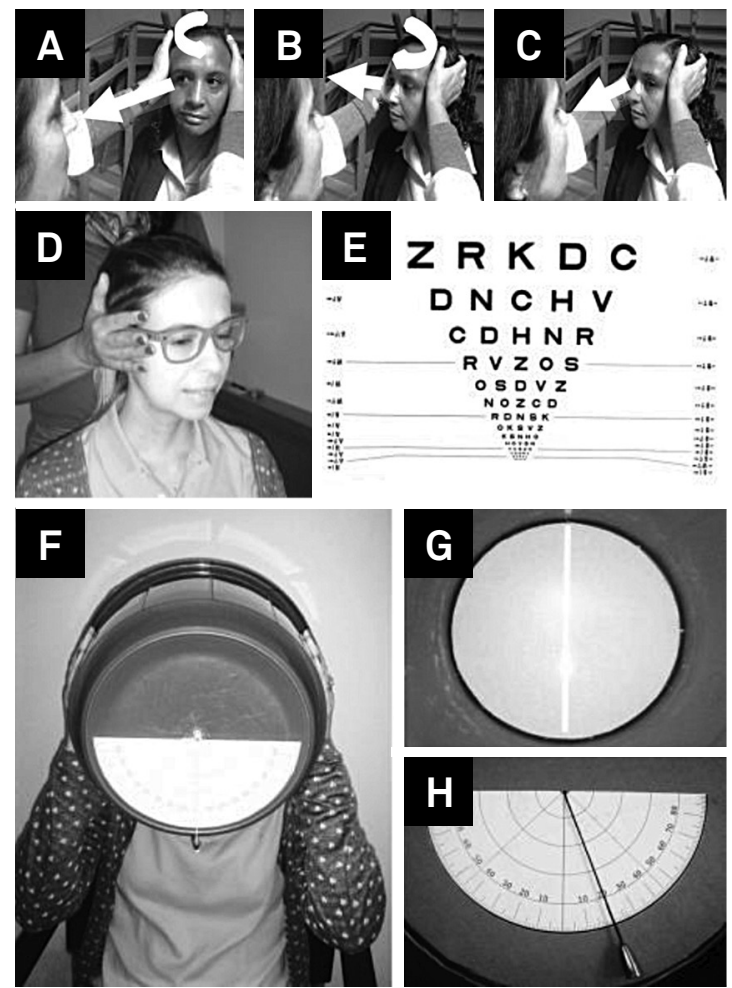

Figure 1. Vestibulo-ocular reflex tests. Head impulse test (A, B, C); dynamic visual acuity (D, E); subjective visual vertical (F, G, H).
FR, indicating that the vestibular postural dysfunctions in migraine cannot be assessed by this test. Observing the FRT response in association with other vestibular-spinal tests we conclude that the anterior tilt does not seem to be particularly affected in migraine.

Given the clearly abnormal result for RTT in migraine patients, it is possible this disease impairs mainly VSR mechanisms, specially involving proprioceptive impulses. Since the RTT preferably tests a side-to-side control, our results are in line with the findings of Góes ${ }^{31}$, in which the laleral oscillation was greater in migraineurs examined by stabilometry.

In the DGI, $13.3 \%$ of patients had a score of less than 19 points, i.e. suggestive of increased FR, while only one control (3.3\%) scored for increased FR. Since this test requires different skills, it may be more sensitive than other FR assessment methods. The PT also shows that migraineurs present postural difficulties in the anteroposterior direction. The anticipatory postural reflexes are specially important in the anteroposterior instability provoked by pulling the patient. The corporal shift deterioration is an important factor for gait desarrangement in the elderly ${ }^{33}$, but this cannot justify the comparatively worse PT results in migraineurs as they were not old. The anteroposterior instability in migraine seems to be better assessed by the PT than by the FRT.

The weaknesses of this work are the relatively small sample, the relatively lower age of patients for FR assessment, the lack of a migraine with vestibular symptoms group and other primary headache groups, and a lack of subsequent testing to confirm results consistency. Due to the high variation of the so-called "vestibular migraine" and the pathophysiological uncertainties related to this diagnosis we believe such patients cannot be selected by reliable criteria yet. Ideally, longitudinal and interventional studies specifically designed to assess vestibular dysfunction in migraine should be perfomed. However, we are confident data are convincing to

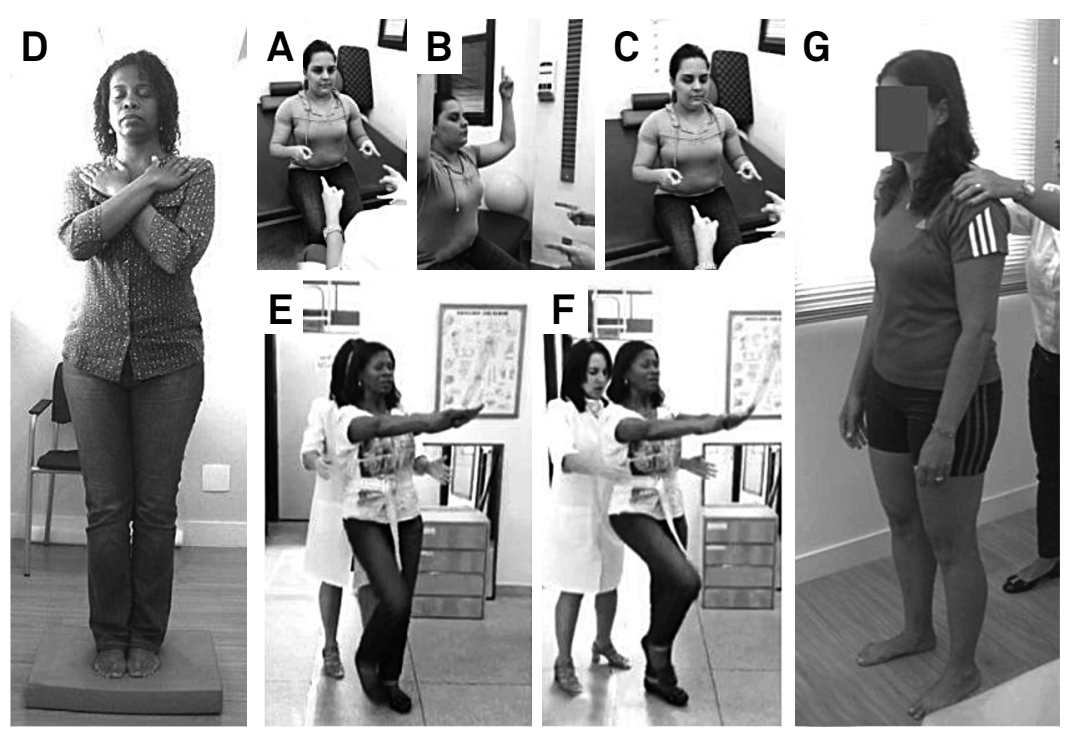

Figure 2. Vestibulo-spinal reflex tests. Past pointing (A, B, C); m-CTSIB step 4 (D); Fukuda test (E, F). fall risk: pull test (G). 


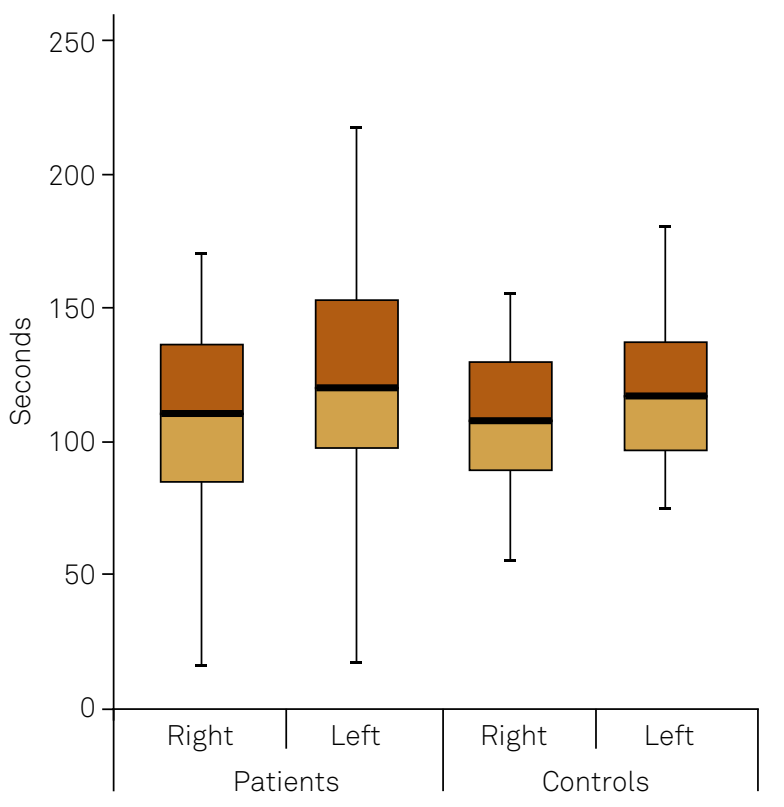

Figure 3. MIT. Patients and controls average nystagmus duration of caloric induced nystagmus in seconds. Box and whiskers plot showing the results of the MIT in seconds. Notice the grater response variability amongst patients. Box right (right ear), left (left ear).
Table 3. Power rating of discrimination scores between migraineurs and controls for different cutoff points.

\begin{tabular}{lcc}
\hline Cutoff points* & Sensitivity & Specificity \\
\hline 1 & $96.7 \%$ & $200 \%$ \\
2 & $70.0 \%$ & $60.0 \%$ \\
3 & $50.0 \%$ & $86.7 \%$ \\
4 & $23.3 \%$ & $93.3 \%$ \\
5 & $20.0 \%$ & $100.0 \%$ \\
6 & $10.0 \%$ & $100.0 \%$ \\
\hline
\end{tabular}

* Positive for values higher or equal to score that counts the number of abnormal results in 13 tests.

demonstrate that migraineurs present subclinical vestibular dysfunctions that may be detected at the bedside. This is in line with the high prevalence of vertigo and unbalance complains amongst migraineurs.

In conclusion, migraine patients consistently showed worse vestibulo-ocular, vestibulo-spinal and FR bedside tests as compared with controls. The results indicate that the vestibular function is impaired subclinically in migraine without vertigo complains. Bedside tests are suitable to detect such dysfunctions. Whether these changes are specific for migraine headaches remains to be determined.

\section{References}

1. Brant T, Dieterich M, Strupp M. Vertigo and dizziness: common complains. London: Springer; 2009.

2. Shepard NT, Asher A. Non-vestibular dizziness and imbalance: suggestions for patients with migraine and mal de débarquement disequilibrium. In: Herdman SJ. Vestibular rehabilitation. 3rd ed. Philadelphia: E.A. Davis; 2007. p. 460-2. (Contemporary perspectives in rehabilitation).

3. Baier B, Winkenwerder E, Dieterich M. "Vestibular migraine": effects of prophylactic therapy with various drugs: a restropective study. J Neurol 2009;256(3):436-42. doi:10.1007/s00415-009-0111-3

4. Lempert T, Neuhauser H. Epidemiology of vertigo, migraine and vestibular migraine. J Neurol. 2009;256(3):333-8. doi:10.1007/s00415-009-0149-2

5. Halmagyi GM, Curthoys IS. A clinical sign of canal paresis. Arch Neurol. 1988;45(7):737-9. doi:10.1001/archneur.1988.00520310043015

6. Asawavichiangianda S, Fujimoto M., Mai M, Desroches H, Rutka J. Significance of head-shaking nystagmus in the evaluation of the dizzy patient. Acta Otolaryngol Suppl. 1999; 540:27-33. doi:10.1080/00016489950181152

7. Herdman SJ, Clendaniel RA. Vestibular rehabilitation. $4 \mathrm{~h}$ ed. Philadelphia: FA Davis; 2014.

8. Zwergal A, Rettinger N, Frenzel C, Dieterich M, Brandt T, Strupp M. A bucket of static vestibular function. Neurology. 2009;7(19)2:1689-92. doi:10.1212/WNL.0b013e3181a55ecf

9. Linthicum Jr FH, Churchill D. Vestibular test results in acoustic tumor cases. Arch Otolaryng. 1968;88(6):604-7. doi:10.1001/archotol.1968.00770010606007

10. Shumway-Cook A, Horak FB. Assessing the influence of sensory interaction of balance: suggestion from the field. Phys Ther. 1986;66(10):1548-50.

11. Baloh RW, Honrubia V. Clinical neurophysiology of the vestibular system. 3rd ed. New York: Oxford University Press; 2001.
12. Barany R, 1910 apud Devin L, McCaslin, Dundas JA, Jacobson GP. The bedside assessment of the vestibular system. In: Jacobson GP, Shepard NT. Balance function assessment and management. San Diego: Plural; 2008. p. 90.

13. Fukuda T. The stepping test: two phases of the labyrinthine reflex. Acta Otolaryngol [Stockh]. 1959;50(1-2):95-108. doi:10.3109/00016485909129172

14. Podsiadlo D, Richardson S. The timed "up \& go": a test of basic functional mobility for frail elderly persons. J Am Geriatr Soc. 1991;39(2):142-8. doi:10.1111/j.1532-5415.1991.tb01616.x

15. Guralnik JM, Simonsick EM, Ferrucci L, Glynn RJ, Berkman LFet al. A short physical performance battery assessing lower extremity function: association with self-reported disability and prediction of mortality and nursing home admission. J Gerontol. 1994;49(2):M85-94. doi:10.1093/geronj/49.2.M85

16. Weiner DK, Duncan PW, Chandler J, Studenski SA. Functional reach: a marker of physical frailty. J Am Geriatr Soc. 1992;40(3):203-7. doi:10.1111/j.1532-5415.1992.tb02068.x

17. Shumway-Cook A, Baldwin M, Olissar NL, Gruber W. Predicting the probability of falls in community dwelling older adults. Phys Ther. 1997;77(8):812-9.

18. Hall CD. Assessment of gait and balance. In: Herdman SJ, Clendaniel RA. Vestibular rehabilitation: a competency-based course. Atlanta: Emory Physical Therapy Association; 2010.

19. Brandt T, Strupp M. General vestibular testing. Clin Neurophysiol. 2005;116(2):406-26. doi:10.1016/j.clinph.2004.08.009

20. Bolay H, Bayazit YA, Gunduz B, Ugur AK, Akçali D, Altunyay S et al. Subclinical dysfunction of cochlea and cochlear efferents in migraine: an otoacoustic emission study. Cephalalgia. 2008;28(4):309-17. doi:10.1111/j.1468-2982.2008.01534.x

21. Dash AK, Panda N, Khandelwal G, Lal V, Mann SS. Migraine and audiovestibular dysfunction: is there a correlation? Am J Otolaryngol. 2008;29(5):295-99. doi:10.1016/j.amjoto.2007.09.004 
22. Baier B, Stieber N, Dieterich M. Vestibular-evoked myogenic potentials in vestibular migraine. J Neurol. 2009;256(9):1447-54. doi:10.1007/s00415-009-5132-4

23. Arriaga MA, Chen DA, Hillman TA, Kunschner L, Arriaga RY. Visually enhanced vestibulo-ocular reflex: a diagnostic tool for migraine vestibulopathy. Laryngoscope. 2006;116(9):1577-9. doi:10.1097/01.mlg.0000231308.48145.f6

24. Çelebisoy N, Gokcay F, Sirin H, Biçak N. Migrainous vertigo: clinical, oculographic and posturographic findings. Cephalalgia. 2008;28(1):72-7. doi:10.1111/j.1468-2982.2007.01474.x

25. Teggi R, Colombo B, Bernasconi L, Bellini C, Comi G, Buss M. Migrainous vertigo: results of caloric testing and stabilometric findings. Headache. 2009;49(3):435-44. doi:10.1111/j.1526-4610.2009.01338.x

26. Marcelli V., Furia T., Marciano E. Vestibular pathways involvement in children with migraine: a neuro-otological study. Headache. 2010; 50(1):71-6. doi:10.1111/j.1526-4610.2009.01454.x

27. Tali D, Menahem I, Vered E, Kalichman L. Upper cervical mobility, posture and myofascial trigger points in subjects with episodic migraine: case-control study. J Bodyw Mov Ther. 2014;18(4):569-75. doi:10.1016/j.jbmt.2014.01.006

28. Schmäl F, Lübben B, Weiberg K, Stoll W. The minimal ice water caloric test compared with established vestibular caloric test procedures.J Vestib Res. 2005;15(4):215-24.

29. Brevern M, Zeise D, Neuhauser H, Clarke AH, Lempert T. Acute migrainous vertigo: clinical and oculographic findings. Brain. 2005:128(2):365-74. doi:10.1093/brain/awh351

30. Akdal G., BalciB. Evaluation of balance in vestibular migraine and migraine patients without history of vertigo. Neurology. 2013;80(meeting abstracts 1):261.

31. Góes CPQF. Avaliação do cerebelo na enxaqueca. Um estudo com estabilometria e ressonância magnética [thesis]. Rio de Janeiro: Universidade Federal do Rio de Janeiro; 2010

32. Davidoff RA. Skeletal muscle tone and the misunderstood stretch reflex. Neurology. 1992;42(5):951-63. doi:10.1212/WNL.42.5.951

33. Nutt JG, Marsden CD, Thompson PD. Human walking and higher-level gait disorders, particularly in the elderly. Neurology. 1993;43(2):268-79. doi:10.1212/WNL.43.2.268 